\title{
A simulation model for designing the automation of future's factory
}

\author{
Prof. Dr. J. Borda Elejabarrieta C.E.O. of Sisteplant Datalde., \\ Professor of Production and Engineering Management Deusto \\ University, Member of I.F.I.P. WG 5.7. \\ Parque Tecnológico Edificio 10548170 ZAMUDIO Spain \\ Phone: (34) 44520611 Fax. (34) 44521266 \\ E-mail: datalde @redestb.es
}

\begin{abstract}
The factory of the future is going to have a high, but not full, degree of automation.

There are three reasons for that. First, no great level of automation is compatible with required flexibility and polyvalence of the processes, regarding the very frequent coming new product versions and changes. The second reason is that product/process integrated evolution is an endless task, and excessive automation could inhibit significative ideas for improvement. And finally, the third one is that the organizational model that advanced technology suggests must be affordable and "resonant" with it. In other words, technology is an "excitation" wave for changing the current organization.

Then, the intention of a manufacturing strategy today is to decide and follow the most convenient degree of automation compatible with flexibility, polyvalence and "the current to desired" organisational model.
\end{abstract}

\section{Keywords}

Logistics and manufacturing strategy, simulation, flexible automation.

Organizing the Extended Enterprise P. Schönsleben, \& A. Büchel (Eds.)

(c) 1998 IFIP. Published by Chapman \& Hall 


\section{INTRODUCTION}

The focus and savings of the increasing logistic costs leads us to consider "logistic strategy first", which practically means that the differentiation between factory's main-synchronised and auxiliary decoupled lines becomes critical at the same time as the rule of making the production lot-size equal to the minimum transferable batch (that is almost always smaller).

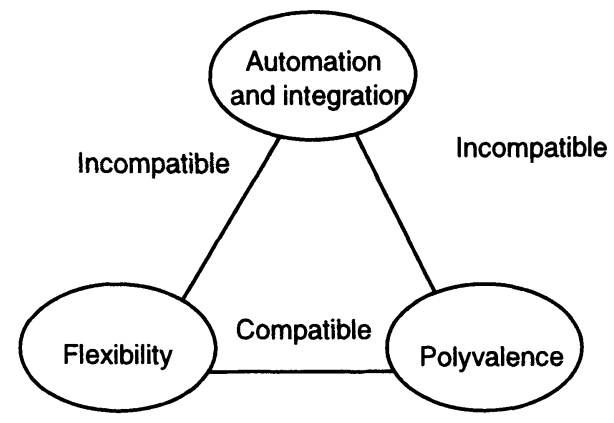

Figure 1: The manufacturing strategy poles. The challenge is to make compatible a flexible polivalent system with an automated integrated one.

Concerning that, the "manufacturing-strategy-poles" (see Figure 1) become critical in the main-synchronized lines (see Figure 2), where the challenge is to build up as much as possible automation compatible with high flexibility for changes in references or volume and a long manufacturing process' life not very sensible to product design changes. Doing that requires an integrated practice with variants strategies, DFM-A and supplier development strategy (See Figure 3 on the previous page).

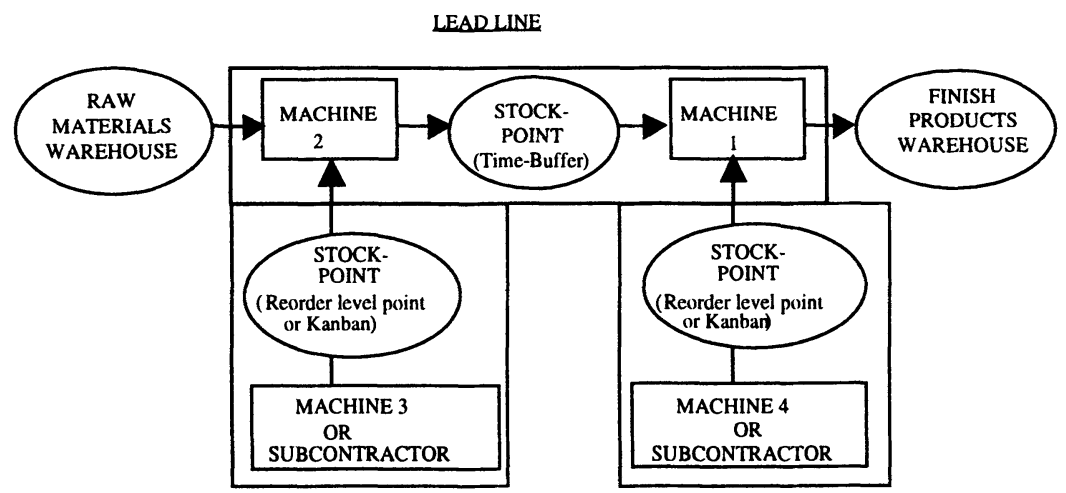

Figure 2: Main and Auxiliary lines. Main syncronized lines conditione the flexibility and lead-time of the facility based on buffer times, and auxiliary lines are decouped from them by reorder level points stocking practices or simply by J.I.T. 
A clear example in the Auto industry is the jig system for the body frame construction so called BIW; ("body in white"). Making a versatile reconfigurable jig gives both flexibility and polivalence at the same time, and no so much investment with the condition of designing appropriated model's frames ready to be welded along with the same adjustable jig. Another example of DFA for the auto industry is the JIT supply of complete sub-assemblies to the main line. Assembling by a robot the entire cockpit, transmissions, the frontal panel, or seats are clear aspects of DFA applied after a tuned logistics and supplier development strategy. If the frame jigs are prepared for mixed model main lines, you will find not less difficult the subassembly feeding systems (cassettes, ramps, and so on) for also different models.

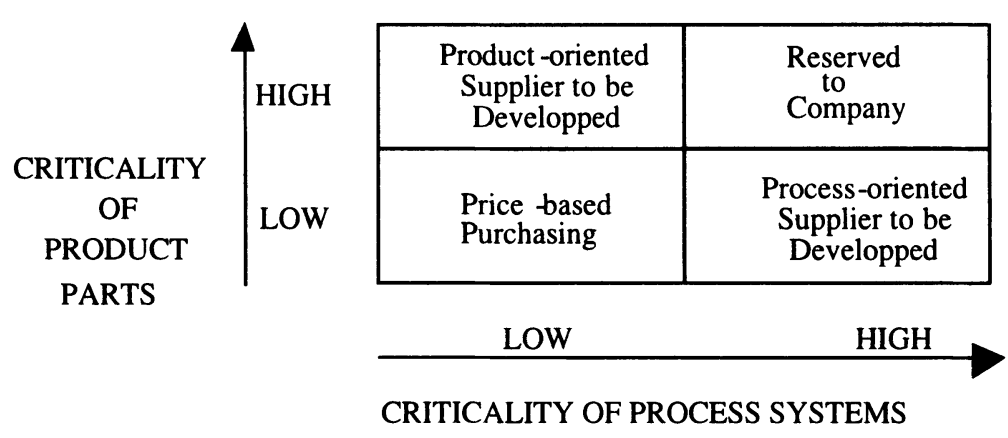

Figure 3: The added-value matrix.

The Figure 3 represents the necessary suppliers development strategy based on technology added value. A high added value technology means the capacity of continuously differentiating both product and process design according to company strategy. When both VAT product and process are high, this piece of the product and process must remain reserved to company.

Then, the area reserved to company corresponds to the main line, the intermediate areas the auxiliary lines based on entire sub-assemblies, and the lowlow area commodity components to be always when possible integrated with the sub-assemblies along the main line.

For auto-makers, the ability of building-up mixed-model polivalent plants (in terms of product-design changes) is a first-class competitive weapon in order to optimize world-wide manufacturing and distribution. This technology could lead in the future to geographically distributed modular mini-plants. 


\section{DEEPING IN THE MANUFACTURING STRATEGY WITH AN EXAMPLE.}

Main line tooling is generally hard tooled-multi-welders or form fixtures, that will only process a particular component or model. A good example of this is the framing operation in the body construction process, where the main body subassemblies are put together to form the body-in-white (BIW), or complete steel structure of or car.

The framing station consists of a hard tooled multi-welder, and clamping configuration and this operation provides the dimensional integrity of the BIW by giving the sub-assemblies in the correct position by the minimum number of spots for this purpose. The remaining spot welds are made by a series of robots after the framing station. The tooling for the framing is very complex and it is considered that such tooling is unlikely to be truly flexible.

One way to achieve flexibility is to use robots in those areas that have historically been limited to hard tooling and multi-welders, like framing. Robots provide great advantages due to re-programmability, and suitability for a wide range of tasks from welding to part handling, but many limitations exists for the use of robots. First physical limitations of load capacity and speed, and second in terms of capacity given that robots can only produce one spot weld at a time, compared to a multi-welder that can produce any number of spot welds simultaneously. To address this problem more than one robot is generally used, but when compared to the investment requirements for hard tooling this may be an unsuitable option.

One case is interesting to be reviewed; the body construction of Toyota. The assembly line is a highly automated production system capable of producing a large number of car models, with the ability to change model production without significative set-up.

The development of the system was based on a number of basic concepts such as measures to improve body accuracy, measures to ensure flexibility, measures to enhance efficiency and streamline production management, measures to simplify the preparatory operation and reduce lead-time.

Body accuracy is improved firstly by restricting the number of spots welds made on the sub assemblies until they reached the final assembly line, where they were fixed with the desired accuracy by applying sufficient welds. Secondly, through the use of a fixture circulation system, that moves fixtures through the assembly processes thus reducing the stack up of tolerances of the sequential assembly processes, when components are moved from one fixture to the next. To ensure flexibility only the circulating fixtures for the underbody, bodysides, roof, and lower back were made model-dependent, and included onto pallets that could carry them around. Hard automation was replaced with robots where ever possible, and for improving efficiency the number of processes was minimised by using a large number of robots in each process and by reducing the part handling processes. This also reduces the variation in the body accuracy by $50 \%$, resulting in a great improvement in quality.

Concerning all those approaches, the Figure 4 contents the components of the manufacturing strategy trade-offs that must be taken into account. 


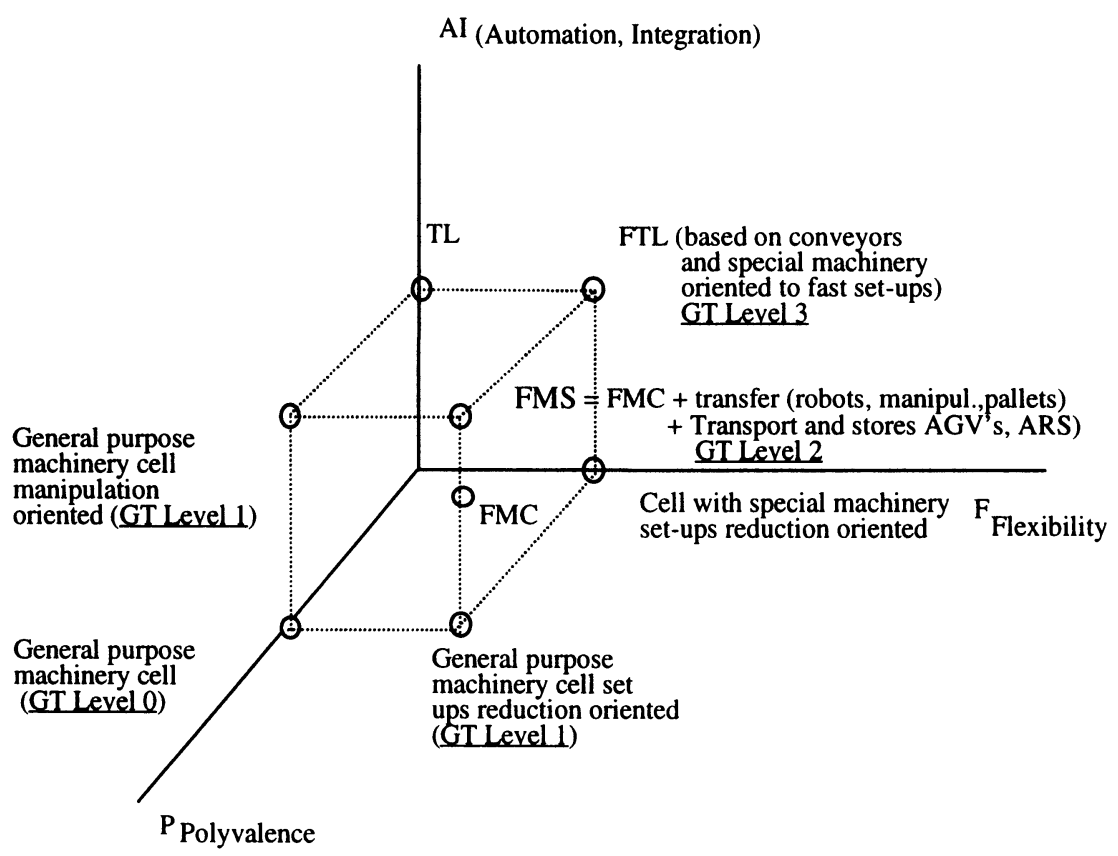

$\mathrm{TL}=$ transfer-line

FTL = flexible transfer-line

FM = flexible manufacturing system

$\mathrm{FMC}=$ flexible manufacturing cell

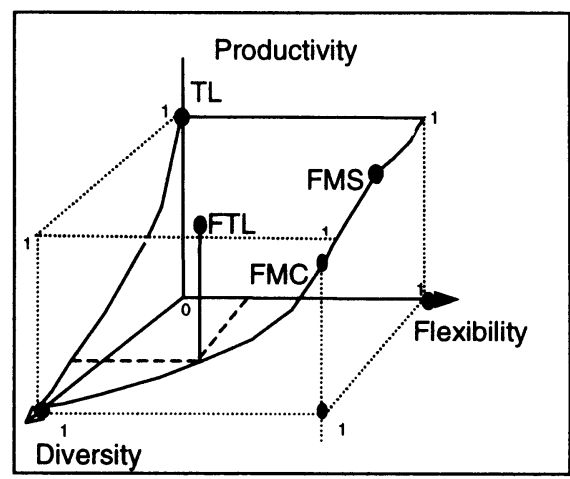

Figure 4: Components of manufacturing strategy trade-offs. 
Flexibility is not only a requirement for facilities and tooling, it is also a requirement for the plant's workforce. For a manufacturer to achieve manufacturing flexibility, it needs to ensure that the workforce are highly skilled, motivated, flexible, and empowered.

The Figure 5 represents the model of resonance. The closer the circles the bigger the resonance.

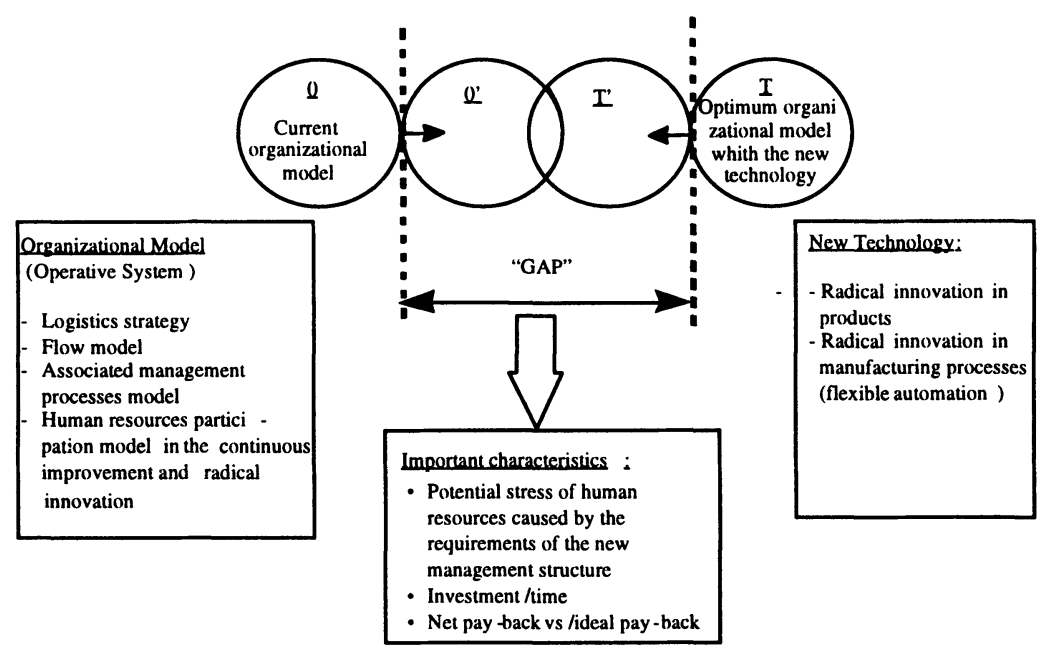

Figure 5: Technology and organizational resonance.

The measurements to closer the gap could be divided into two categories:

a) Moving from 0 to $0^{\prime}$

* Extensive technological training:

- Give sense of maximum potential with pilot trials or simulation virtual reality simulation.

- Defining the tasks of technological management (all members of the organization manage technology in some way).

* Representing changes of management processes through a simulation software and redesigning interactively, in convenient groups.

b) Moving from $T$ to $T^{\prime}$

* Setting up limits to the automation in order to do not rigidice product and process further improvements.

* Generating product innovation focused on new challenges for the automation (short series, customization).

* Appropriated man/machine interfaces in order to do not forget basic skills of plant operation people. 


\section{THE MODEL FOR SIMULATION AND AN EXAMPLE}

Figure 6 is a flow chart of the proposed simulation model. An example is given for the design of a new facility plant for syntherized metal parts.

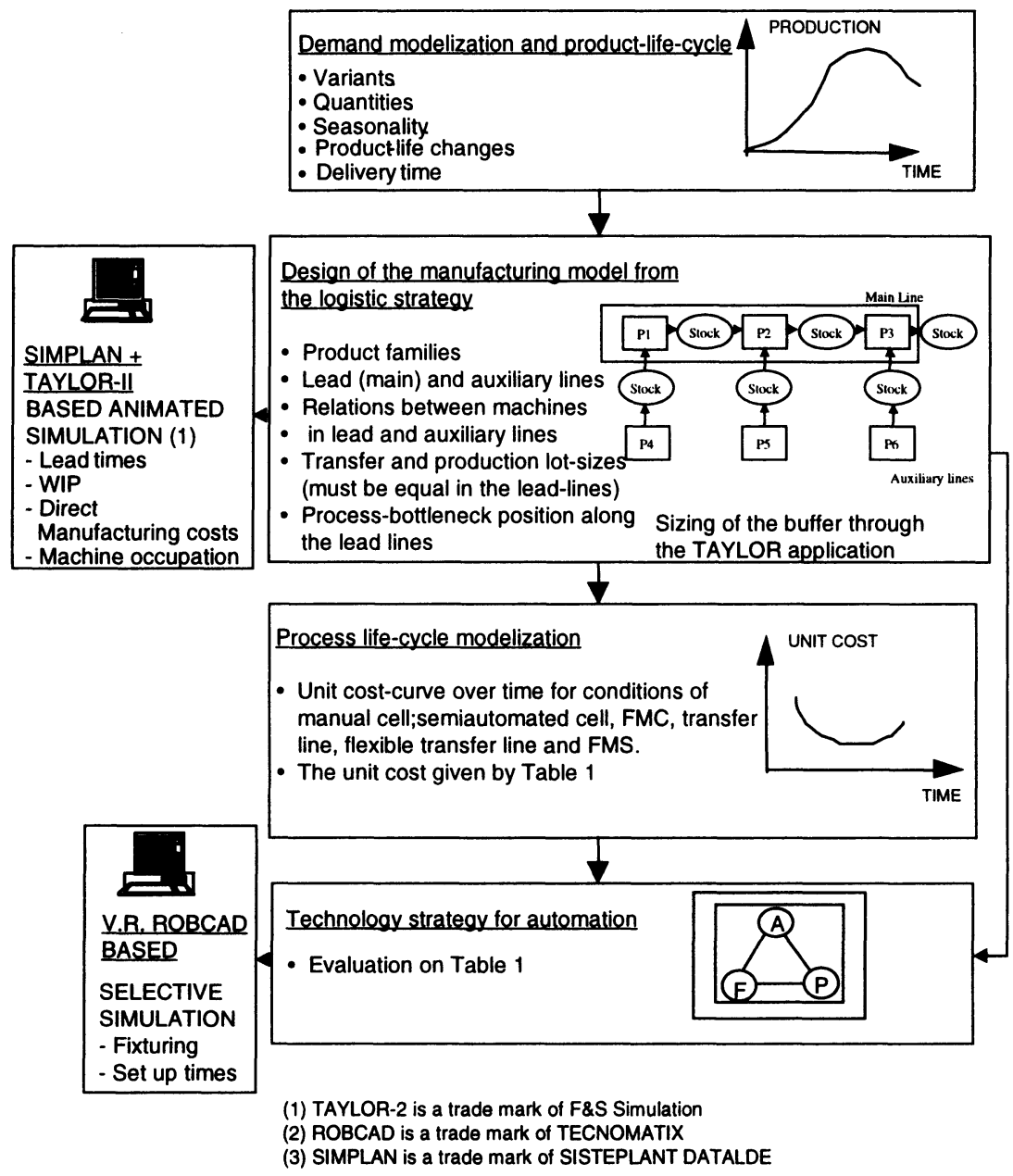

Figure 6: Flow chart describing the simulation model. 
The inputs for the modelization of the demand and determination of the product's cycle life are the following:

Valves and pistons (14 millions of pieces), pumps (8 millions of pieces), guides and assemblies (13 millions of pieces).

The demand pattern is stable with picks of production before the summer, the product's cycle is 5 years and delivery is one week with frequent changes of programming.

The design of the manufacturing lines for 20 different produced items is represented in Figure 7, and a typical product in Figure 8.

Design of the main line:

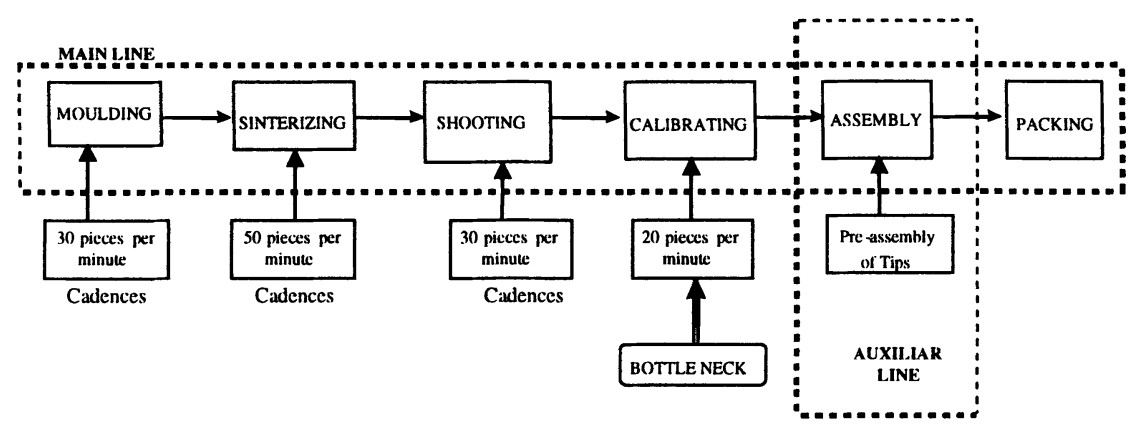

Figure 7: The main and aux. lines

The transfer processes have two critical points:

a) Transfer from moulding to sinthering furnaces.

b) The simultaneous manufacturing of 5 references.

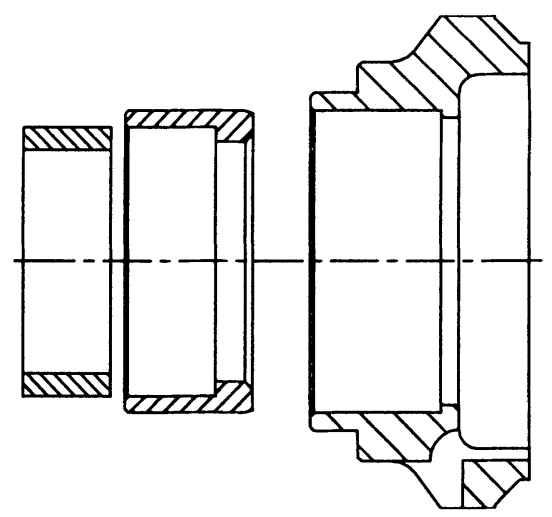

Figure 8: Guide Components. 
These considerations affect selection of a manipulating method. Using carrying belts involves that it is not possible redirectioning mouldings to sinthering furnaces and that the system is limited to a transference piece to piece.

Then, the alternative selected is to transfer in trays through a guided vehicle, which allows transference of parts' trays and the possibility of redirectioning. This last is the selected option to be simulated.

Design of the auxiliary line

The auxiliar line incorporates a pre-assembly, to the main line. This preassembly is composed of two tips which are purchased externally. Both tips are mounted in an independent machine of the main line. It is critical in this process the sizing of concepts such as the order point for the :

- Tips purchase.

- Intermediate buffer.

And the assembly batch for the pre-assembly operation.

TAYLOR simulator allows the sizing of those concepts. It is fed by the following data: rate of assembly in the main line, rate of pre-assembly both assemblies set up times, tips delivery times.

The evolution of the buffer level and the manufacturing rate between desincronized processes (assembly on the main-line and the preassembly on the auxiliary line) are set-up through the simulation.

The checking of the line's design is arranged as follows:

Simulation plays an important role in checking the design of the line. Possible incidences like machines breakdowns or changes in the manufacturing plan could be solved by redirectioning production to other machines. It is here where simulation is of a great help.

A modified manufacturing plan is set facing a redistribution of manufacturing orders among different machines. SIMPLAN could be used for this purpose as it takes into account capability of the machines. After manufacturing orders are generated, they are sent to a virtual shop-floor (TAYLOR) where manufacturing costs and storage room requirements are studied. An iterative process results in the definitive (or at least more accurate) design of the line.

The above mentioned simulation study could be completed by using a third simulator, ROBCAD, which optimizes working places.

It provides a diverse set of studies: lifting and carrying analysis, weight limits, posture analysis, energy expenditure, arm strength analysis and time analysis (MTM 1).

This last feature (time analysis using MTM 1) is used to optimize human or robotized operation cycle time and may be used as a feed-back operation for the TAYLOR simulation to resize the buffer between PREASSEMBLIES and ASSEMBLY in the current example.

Again, the iterative design results in the definitive design of the line and an optimized process. 


\section{MODELLING THE CURVE COST-AUTOMATION LEVEL CYCLE'S LIFE}

Two options are considered to automate the transference from moulding presses to sinthering furnaces. The first one consists of the utilization of belts that connect directly the output point of the press with the input point of the furnace. Parts are driven on the belt one by one. Five furnaces are placed in front of the five presses. Since each press is connected directly to the nearest furnace, the output can hardly be redirectioned to another furnace.

Lower investment and the fact that it is a known transfer system are the most important advantages of this system. Lower flexibility and therefore, lower productivity present like main disadvantages.

The second option consists of the utilization of a guided vehicle which allows the connection of any press with any furnace. Trays sized $600 \mathrm{~mm} \times 400$ $\mathrm{mm}$ are used to stock the parts in the output point of each press. Once one of these trays of any press is full, a signal coming from the PLC orders to the guided vehicle the origin and the destination furnace of the tray.

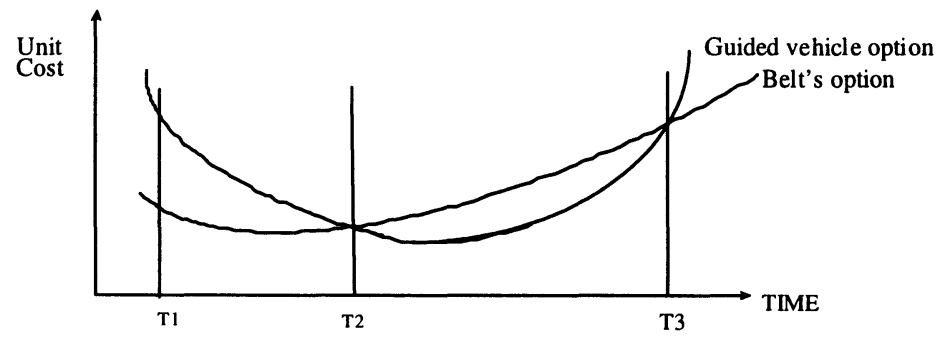

Figure 9: Curve cost-automation level cycle's life

High investment is its main disadvantage, and flexibility and wider possibilities of changing the lay-out in the future are the great advantages.

To make the comparison between both systems three times have been considered in Figure 9.

$\mathrm{T} 1<\mathrm{T}<\mathrm{T} 2$ : Unit Cost Guided Vehicle $>$ Unit Cost Belts

$\mathrm{T} 2<\mathrm{T}<\mathrm{T} 3$ : Unit Cost Belts $>$ Unit Cost Guided Vehicle

$\mathrm{T}>\mathrm{T} 3 \quad$ : Unit Cost Guided Vehicle $>$ Unit Cost Belts

$\mathrm{T} 1$ is the start-up time, when both the cost of the set-up time and net investment are the weighty arguments to set unit cost of the guided vehicle option higher.

$\mathrm{T} 2$ is the time when additional investments, higher in belts option, begin to have a crucial weight to make unit cost of the belts grow higher. These additional investments are caused by lower polivalence in the belt's option.

$\mathrm{T} 3$ is the time when maintenance costs of the guided vehicle option, make its unit costs be higher than the belt's option as they become exponential.

Numerical values are explained in chapter 6. 
The technological strategy for automation should be one that balanced the "machine triangle", that is to say, possible system with a guarantee of flexibility and polivalence.

\section{LOGISTIC STRATEGY BETWEEN PRESSES AND SINTHERING FURNACES}

The following table 1 shows values of the parameters that were taken into account when evaluating the current example.

Table 1

\begin{tabular}{lrr}
\hline & Belts & $\begin{array}{r}\text { Guided } \\
\text { Vehicle }\end{array}$ \\
\hline 1. Capacity (Million parts year) & 13 & 14,95 \\
2. Variable Maintenance Costs (\$/year) & 2500 & 7000 \\
3. Process oriented investments (corresponding to \\
$\begin{array}{l}\text { periods of target cycle life without changes) } \\
\text { (\$/year) }\end{array}$ & 25.500 & 6.896 \\
4. Net investments (\$repayment/year) & & \\
$\begin{array}{l}\text { Belts: five years repayment } \\
\text { Guided Vehicle: Ten years repayment }\end{array}$ & 27.586 & 20.700 \\
5. Unit Costs (\$) & & \\
\end{tabular}

1. The number of parts produced has been obtained considering extraproductivity $(20 \%)$ of the guided vehicle option, based on its polivalence (i.e.: any pressed part could be processed in any furnace) and also the lower availability of the guided vehicle system (5\%). (Any breakdown of the guided vehicle leads to a full stop of the cellule).

2. These costs are higher in the guided vehicle option. This is caused by the complexity of the electronic and mechanical components of the vehicle. After T3 (Figure 9) these costs grow exponentially and leads to much higher unit costs.

3. Process oriented investments corresponding to periods of the target cycle life without changes are higher in the belt's option where, for instance, the increase of the production volume motivates the growth in number of presses and non-polivance of the belt's option leads to a much more complicated solution. (When production has to be directioned from 8 presses to 6 furnaces, a new belt system has to be implemented as there are two presses without belts).

4. The cycle life of the belt system is shorter since they have to be changed whenever there is a process automation change.

5. In this calculation only costs that could imply a significant difference between both options are considered. Costs like labour and energy costs have not been considered.

The flexibility and polivacence given by the guided vehicle option makes this point more economical in the whole period T1-T3. Just after this point time (T3), and due to the maintenance costs the guided vehicle option becomes less interesting. 


\section{CONCLUSIONS AND FURTHER WORK}

Logistics' strategy, manufacturing strategy and flexibility are crucial aspects to be considered together. To do that in an effective way the concept of main and auxiliary lines is of a great help in order to set up tuned and clearly differentiated supply, handling and automation strategies.

Further development is being carried out in order to integrate software tools for rapid redesign of plant lay-outs and automation. A low-cost CAD-2D/3D (Autocad), a simulator of material flow (Taylor-2), a simulator for cell or workplace automation (Robcad), and the Imagim + GRAI based simulation tool for production management systems are being studied by the GRAI-LAP (Bordeaux) and the $R+D$ department of SISTEPLANT DATALDE in order to implement an operative integrated tool.

\section{REFERENCES}

Doumeingts, G., (1984). Méthode GRAI, méthode de conception des systèmes en productique. Doctoral Thesis, Université Bordeaux 1.

Zanettin, M., (1994). Contribution à une méthode de conception de systèmes de production. $\mathrm{PhD}$ Thesis, Université Bordeaux 1.

Mertins, K., Jochem, R. (1992) An object Oriented Method for Integrated Enterprise modelling as a Basis for Enterprise Coordination. International Conference on Enterprise Integration Modeling Technology (ICEIMT). Hilton Head (South Carolina), US Air Force-Integration Technology Division.

\section{BIOGRAPHY}

Prof. Dr. Javier Borda Elejabarrieta has been working as plant Engineer and Production Manager staff for 7 years, and from 1984 he is the managing director and C.E.O. of DATALDE, S.A., a spanish 35 people industrial engineering company, sited in the Basque Country. He read in 1989 the Doctoral Mechanical Engineering dissertation on "CIM for plastic injection workshops". He is also Professor of Production and Engineering Management in the University of Deusto, Bilbao, and the author of several international papers and a book titled: "Advanced Maintenance Techniques" (1990). He has become recently an IFIP WG 5.7 member. 